\title{
COMPARISON OF THIMEROSAL EFFECTIVENESS IN THE FORMULATION OF EYE DROPS CONTAINING NEOMYCIN SULFATE AND CHLORAMPHENICOL
}

\author{
MARLINE ABDASSAH ${ }^{1}$, SRI AGUNG FITRI KUSUMA ${ }^{2 *}$
}

1Departement of Pharmaceutics, Faculty of Pharmacy, Padjadjaran University, Sumedang, West Java, Indonesia 45363, ${ }^{2}$ Department of Biology Pharmacy, Faculty of Pharmacy, Padjadjaran University, Sumedang, West Java, Indonesia 45363

Email: s.a.f.kusuma@unpad.ac.id

Received: 27 Sep 2018, Revised and Accepted: 19 Nov 2018

\section{ABSTRACT}

Objective: This study was aimed to compare the preservative efficacy of thimerosal in eye drops formulation containing neomycin sulfate and chloramphenicol as the active agents.

Methods: Determination of thimerosal concentration in combinations with chloramphenicol and neomycin sulfate was carried out using the agar diffusion method. Then the thimerosal ineffective and minimal concentration was formulated into eye drops, each with $0.5 \%$ neomycin sulfate and $0.5 \%$ chloramphenicol as the active ingredient. Evaluation of eye drops was carried out for $28 \mathrm{~d}$, which included: visual observation, $\mathrm{pH}$ measurement, sterility, and effectiveness test.

Results: Thimerosal at a minimum concentration of $0.001 \%$ remain to provide antibacterial activity against common eyes contaminants. Both eyes drops containing neomycin sulfate, and chloramphenicol resulted in clear solution, sterile, and stable in the pH and antibacterial potency,showed the efficacy of thimerosal's role in eye drops at the lowest concentration. But, the thimerosal stability as a preservative agent was affected by the $\mathrm{pH}$ values of the eye drops solution. Therefore, the effectivity of thimerosal in chloramphenicol (pH 7.19-7.22) was better than neomycin sulfate (6.456.60). Compared with F0 (without thimerosal), the increasing of inhibitory diameter in F1 and F2 from both eyes drops formula exhibited the significant role of thimerosal as the preservative agent. The synergistic effect of the preservative agent in the formula produced a better product stability than the eye drop without thimerosal.

Conclusion: Thimerosal at a minimum concentration of $0.001 \%$ exhibited effective concentration as a preservative in eye drops containing $0.5 \%$ neomycin sulfate and $0.5 \%$ chloramphenicol.

Keywords: Thimerosal, Eye drops, Neomycin sulfate, Chloramphenicol

(C) 2019 The Authors. Published by Innovare Academic Sciences Pvt Ltd. This is an open access article under the CC BY license (http://creativecommons.org/licenses/by/4.0/) DOI: http://dx.doi.org/10.22159/ijap.2019v11i1.30012

\section{INTRODUCTION}

The eyes are parts or tools of the body that are highly sensitive to external influences. The, therefore, the eye needs treatment to function properly and does not experience infection. Eye infections occur when pathogenic microorganisms in the form of viruses, bacteria, fungi, or parasites multiply in the eye. The eye infections are majority contributed from exogenous contaminants and also related to microbial air pollution from indoor environment and seasonality [1-3]. The airborne contaminants that spread through the hands can be an alternative source of eye infection that is meaningful [4]. Moreover, the eye contaminant may come from the used of ophthalmic solutions. The eye infections caused by contaminants from air pollution, contaminated ophthalmic medications or other reasons, lead damage to the functional structures of the eyes and may cause blindness [5-7]. Others eyes infections such as endophthalmitis and bacterial keratitis were reported to be correlated with the use of contaminated topical eye medications $[8,9]$. The bacterial contaminants in ophthalmic solutions may alter the $\mathrm{pH}$ preparation and lead to reducing the medical efficacy of the treatment [10]

The ophthalmic product solutions have been reported to be contaminated with pathogens and caused ocular infections [11]. Several studies reported that bacterial contamination rates in ophthalmic solution bottles were in ranged of $2.3-70 \%$ with commonly isolated bacteria such as: Pseudomonas, Staphylococcus aureus, coagulase-negative Staphylococcus, Bacillus, Enterobacter, Proteus, Klebsiella spp and Serratia [12-15]. These reports were supported by other research that examined 92 eye drop bottles: 43 bottles were opened and used, and 49 bottles were sealed. The results showed that the contamination rates were higher obtain from the opened bottle than unopened bottles. The coagulasenegative Staphylococci, S. aureus, and Bacillus, were found as contaminants from both eye drop bottle treatment [16]. Another study also reported that the contamination sources in eye drop product were mostly from the caps $(45.9 \%)$, from droppers $(41.0 \%)$ and residual contents (13.1\%) [17]. Therefore, most ophthalmic preparations always use preservatives to inhibit the growth of microbial contamination.

The main function of preservatives is to decrease the risk of infection by preventing the growth of microorganisms which can cause degradation of the drug; thus, the product sterility is assured and maintained during use. In eye care, besides preservative has to kill microbes, but several preservatives can cause a little bit of toxicity to the ocular surface. Thimerosal is one of common preservative, used in eye drops preparation. But in vaccine preparation, because of its organic-mercury $(\mathrm{Hg})$ based compound in thimerosal, it was reported to be harmful. In contrast, the United States Centers for Disease Control and Prevention states that Thimerosal is safe and there is no relationship between thimerosalcontaining vaccines and autism rates in children [18]. Therefore, considering the efficacy of thimerosal as preservatives in eye drops preparation, this study concerned with the determination of the low concentration of thimerosal that remains effectively in preventing the contaminant growth.

In this study, the efficacy of thimerosal as a preservative was tested on two eye drop formulas, each containing neomycin sulfate, and chloramphenicol antibiotics. Neomycin is a commonly useful antibiotic for ocular use and has broad spectrum against Grampositive and Gram-negative bacteria. In addition, than polymyxin B, neomycin is more effective against Proteus vulgaris [19]. Neomycin sulfate eye drops in repeated use (multi doses) which do not contain preservatives are reported to be ineffective. However, the use of chloramphenicol as an antibiotic in an ophthalmic preparation is the gold standard and being prescribed in $55 \%$ of red eyes $[20,21]$. The efficacy of chloramphenicol has achieved of $91 \%$ to $93 \%$ in ocular 
infections [22,23] and effectively inhibit up to $94 \%$ eye pathogens [20]. The efficacy of chloramphenicol was supported because of its high differential solubility resulting in high intraocular penetration. Chloramphenicol also has a superior effect to most other antibiotics for prophylaxis in ocular surgery $[21,24]$.

\section{MATERIALS AND METHODS}

\section{Materials}

The microbes used in this study were Staphylococcus aureus, $S$. epidermidis, Pseudomonas aeruginosa, Bacillus subtillis and Candida albicans were obtained from the Microbiology Laboratory, Faculty of Pharmacy, Padjajaran University and Pathology Laboratory of Hasan Sadikin Hospital Bandung. Indonesia. The kinds of microbial growth medium used were Mueller Hinton Agar/MHA (Oxoid), Mueller Hinton Broth/MHB (Oxoid), Fluid Thioglicolate Medium/FTM (Oxoid), and Soybean Casein/SC (Pronadisa). The chemicals used were the antibiotic neomycin sulfate (PT. Cendo Indonesia),disodium hydrogen phosphate (Merck), disodium phosphate (PT. Brataco Indonesia), sodium chloride(Merck), disodium edetate (J. T. Baker), sodium metabisulfite (PT. Brataco Indonesia), thimerosal (PT. Cendo Indonesia), sodium tetraborate (Merck), boric acid (Merck) and redistillata water (PT. Ikapharmindo Indonesia).

\section{Preparation of microbial suspension}

One Ose of each bacterial colony was suspended in MHB and incubated at $370 \mathrm{C}$ for $18 \mathrm{~h}$. The final bacterial inoculum concentration was adjusted to $0.5 \mathrm{Mc}$ Farland $\left(1.5 \times 10^{8}\right.$ (cfu/ml) [25]. McFarland solution consisted of two components, $1 \% \mathrm{BaCl}_{2}$ and $1 \%$ $\mathrm{H}_{2} \mathrm{SO}_{4}$. A total of $0.05 \mathrm{ml}$ of $1 \% \mathrm{BaCl}_{2}$ solution was mixed with 9.95 ml of $1 \% \mathrm{H}_{2} \mathrm{SO}_{4}$ solution and shaken homogeneously. The turbidity of the solution was measured at a wavelength of $530 \mathrm{~nm}$ by using distilled water as a blank [26].

\section{Determination of thimerosal concentration}

Determination of the minimum concentration of thimerosal in two eye drop formulas which each contained $0.5 \%$ neomycin sulfate antibiotics and $0.5 \%$ chloramphenicol were carried out using the agar diffusion method. The variation of thimerosal concentration used to be as follows: $0.02 \% ; 0,015 \% ; 0.01 \% ; 0.005 \%$ and $0.001 \%$. A total of $20 \mu \mathrm{l}$ bacterial suspension was poured intoa sterile petri dish containing MHA $\left(45{ }^{\circ} \mathrm{C}\right)$, then the bacterial suspension was homogenized and allowed to solidify at room temperature. The media were then perforated using perforator aseptically. Each hole was filled with $50 \mu \mathrm{l}$ of each formula solution and incubated for $18 \mathrm{~h}$ at $37^{\circ} \mathrm{C}$. The combined antibacterial activity was compared with the antibacterial activity of neomycin sulfate/chloramphenicol and thimerosal in a single state. The inhibitory diameters were measured using a caliper [27].

\section{Eye drops formulation}

The eye drop formulation consisted of a positive control formula (F1) with a $0.01 \%$ preservative concentration, a tested formula (F2) with a concentration of $0.001 \%$ thimerosal, and a negative control formula (F0) made without using thimerosal.

The aim of this design experiment procedure was to evaluate the efficacy of eye drops with thimerosal preservatives at $0.001 \%$ against negative controls and to determine the effect of differences in thimerosal concentration compared with positive controls. Eye drops preparation formulations can be seen in table 1 and 2 .

Table 1: $0.5 \%$ neomycin sulfate eye drop formula

\begin{tabular}{|c|c|c|c|}
\hline Composition & F0 (\%) & F1 (\%) & F2 (\%) \\
\hline Neomycin sulfate & 0.50 & 0.50 & 0.50 \\
\hline Sodium Dihydrogen Phosphate & 0.70 & 0.70 & 0.70 \\
\hline Disodium phosphate & 0.70 & 0.70 & 0.70 \\
\hline Sodium chloride & 0.40 & 0.40 & 0.40 \\
\hline Disodium edetate & 0.10 & 0.10 & 0.10 \\
\hline Thimerosal & 0.00 & 0.01 & 0.001 \\
\hline Sodium metabisulfite & 0.20 & 0.20 & 0.20 \\
\hline Sterile aqua pro injection (API) & Ad 100 & Ad 100 & Ad 100 \\
\hline
\end{tabular}

The formulation process of mixing ingredients for $0.5 \%$ neomycin sulfate eye drops were carried out in the Laminar Air Flow (LAF) room. Neomycin sulfate, disodium Hydrogen Phosphate, sodium chloride, disodium edetate, and disodium Phosphate were dissolved in a part of the sterile aqua pro injection (API). After that, the thimerosal solution was added. After all, components were mixed, the API was added, and then the $\mathrm{pH}$ solution was measured. The solution was then sterilized using a bacterial filter. After that, the sterilized preparations were stored at temperature room and protected from the sun.

Table 2: $0.5 \%$ Chloramphenicol eye drop formula

\begin{tabular}{llll}
\hline Composition & F0 (\%) & F1 (\%) & F2 (\%) \\
\hline Chloramphenicol & 0.50 & 0.50 & 0.50 \\
Boric acid & 1.50 & 1.50 & 1.50 \\
Sodium tetraborate & 0.30 & 0.30 & 0.30 \\
Thimerosal & 0.00 & 0.01 & 0.001 \\
Sterile aqua pro injection (API) & Ad 100 & Ad 100 & Ad 100 \\
\hline
\end{tabular}

For chloramphenicol eye drops formula, the chloramphenicol, boric acid, and sodium tetraborate were dissolved in a part of sterile API, then the thimerosal solution was added. Then remaining API was mixed with the mix ingredients and homogenized. Then the $\mathrm{pH}$ solution was measured. The solution was then sterilized using a bacterial filter.

\section{Evaluation of eye drops}

Evaluation of eye drops was carried out for $28 \mathrm{~d}$, which included: visual observation, $\mathrm{pH}$ measurement, sterility and effectiveness test.

\section{Clarity observation}

The clarityinspection of eye drops was done by observing the clarity and color change of each container of eye drop preparations, with an observation time on days of $1,3,7,14,21$ and 28 during storage.

\section{pH}

$\mathrm{pH}$ of the prepared eye drops solution was measured by a $\mathrm{pH}$ meter. 


\section{Sterility test}

The eye drops bottle was aseptically opened and pipetted of 2 $\mathrm{ml}$. Each of $1 \mathrm{ml}$ sample was inoculated into the FTM and TSB medium. Each test media were then incubated for $14 \mathrm{~d}$ at 30-35 ${ }^{\circ} \mathrm{C}$ for FTM media, and at a temperature of $20-25{ }^{\circ} \mathrm{C}$ for TSB media. As a positive control both Bacillus subtilis and Candida albicans inoculated into the appropriate test media. FTM media were used for bacterial examination and used B. subtilis as the positive control. Meanwhile, TSB medium was used for examination of fungal contamination and used $C$. albicans as the positive control [28].

\section{Efficacy test}

A total of $20 \mu \mathrm{l}$ bacterial suspension was poured into a sterile petri dish containing MHA $\left(45^{\circ} \mathrm{C}\right)$, then the bacterial suspension was homogenized and allowed to solidify at room temperature. The media were then perforated using perforator aseptically. Each hole was filled with $50 \mu \mathrm{l}$ of each formula solution and incubated for $18 \mathrm{~h}$ at $37^{\circ} \mathrm{C}$. The inhibitory diameters were measured using a caliper.

\section{Statistical analysis}

The effectivity data result was analyzed using Analysis method of Variance (ANOVA) for 3-factor factorial experiments. Where factor A was a group of bacteria, factor B was a group of formulas, and factor $\mathrm{C}$ was a group storage period. This test was intended to analyze if there were any a significant difference in the effect of the three types of treatment groups. Followed by Student Newman Keuls Test (S-N-
$\mathrm{K}$ Test) to determine the most stabile eye dropsformula from neomycin sulfate and chloramphenicol eye drops.

\section{RESULTS AND DISCUSSION \\ Determination of thimerosal concentration}

Preservatives used in both eye drop preparation formulations served to prevent contamination and growth of pathogens during storage and use. This is an important agent to be formulated because while in use; microbial contamination may happen and lead to ocular infection or product degradation [17]. Therefore, protection of the product, an especially sterile product like an eye drops is essential to improve the product against the opportunistic contamination effects by using appropriate preservatives. Thimerosal is one of common preservative, use in eye drops preparation. In eye care, beside preservative has to kill microbes, but several preservatives can cause a little bit of toxicity to the ocular surface. Because of its organic-mercury $(\mathrm{Hg})$ based compound in thimerosal, thimerosal was reported to be harmful. In contrast, the United States Centers for Disease Control and Prevention states that Thimerosal is safe and there is no relationship between thimerosal-containing vaccines and autism rates in children [18]. Therefore, considering the efficacy of thimerosal as preservatives in eye drops preparation, this study concerned with the determination of the low concentration of thimerosal that remain effective in preventing the contaminant growth. Based on the antibacterial test, the inhibition effects of thimerosal in different concentration against $S$. aureus, $S$. epidermidis and P. aeruginosa, were performed in the table 3-4.

Table 3: Effect thimerosal inhibition as a preservative in $0.5 \%$ neomycin sulfate eye drops

\begin{tabular}{llll}
\hline Formula & \multicolumn{2}{l}{ Diameter of inhibition (mm) } & P. aeruginosa \\
\cline { 2 - 4 } & S. aureus & S. epidermidis & $25.7 \pm 0.060$ \\
FA & $34.6 \pm 0.000$ & $25.8 \pm 0.000$ & $23.1 \pm 0.000$ \\
FA1 & $31.5 \pm 0.060$ & $25.0 \pm 0.000$ & $26.7 \pm 0.040$ \\
FB & $31.5 \pm 0.000$ & $26.0 \pm 0.000$ & $25.4 \pm 0.000$ \\
FB1 & $25.9 \pm 0.040$ & $21.3 \pm 0.035$ & $22.6 \pm 0.000$ \\
FC & $30.0 \pm 0.020$ & $24.5 \pm 0.050$ & $21.2 \pm 0.020$ \\
FC1 & $26.4 \pm 0.000$ & $21.9 \pm 0.000$ & $20.3 \pm 0.030$ \\
FD & $27.7 \pm 0.030$ & $22.4 \pm 0.015$ & $14.8 \pm 0.000$ \\
FD1 & $24.3 \pm 0.030$ & $19.2 \pm 0.000$ & $19.6 \pm 0.020$ \\
FE & $24.0 \pm 0.000$ & $14.7 \pm 0.000$ & $16.9 \pm 0.000$ \\
FE1 & $17.1 \pm 0.000$ & $13.1 \pm 0.015$ & \\
\hline
\end{tabular}

Notes: Staphylococcus aureus (SA); Staphylococcus epidermidis (SE); Pseudomonas aeruginosa (PA); 0.5\% neomycin sulfate+0.02\%Thimerosal (FA); $0.02 \%$ Thimerosal (FA1); $0.5 \%$ neomycin sulfate $+0.015 \%$ Thimerosal (FB); $0.015 \%$ Thimerosal (FB1);0.5\% neomycin sulfate $+0.01 \%$ Thimerosal (FC);0.01\% Thimerosal (FC1);0.5\% neomycin sulfate $+0.005 \%$ Thimerosal (FD);0.005\% Thimerosal (FD1);0.5\% neomycin sulfate+0.001\%Thimerosal (FE); 0.001\%Thimerosal (FE1); Each number of experiment replication=3, Diameter of inhibition (mean \pm SD)

Table 4: Effect thimerosal inhibition as a preservative in $0.5 \%$ chloramphenicol eye drops

\begin{tabular}{llll}
\hline Formula & \multicolumn{2}{l}{ Diameter of inhibition (mm) } & P. aeruginosa \\
\cline { 2 - 4 } & S. aureus & S. epidermidis & $31.0 \pm 0.080$ \\
FA & $39.4 \pm 0.010$ & $32.4 \pm 0.000$ & $26.8 \pm 0.005$ \\
FA1 & $38.2 \pm 0.005$ & $27.3 \pm 0.015$ & $29.0 \pm 0.100$ \\
FB & $39.0 \pm 0.055$ & $32.1 \pm 0.020$ & $21.0 \pm 0.005$ \\
FB1 & $36.8 \pm 0.065$ & $26.6 \pm 0.045$ & $30.2 \pm 0.090$ \\
FC & $38.3 \pm 0.005$ & $31.5 \pm 0.005$ & $22.0 \pm 0.000$ \\
FC1 & $30.9 \pm 0.050$ & $22.4 \pm 0.005$ & $26.4 \pm 0.005$ \\
FD & $36.7 \pm 0.020$ & $30.4 \pm 0.005$ & $21.3 \pm 0.005$ \\
FD1 & $30.6 \pm 0.020$ & $17.5 \pm 0.005$ & $26.9 \pm 0.020$ \\
FE & $34.8 \pm 0.045$ & $29.3 \pm 0.005$ & $12.4 \pm 0.000$ \\
FE1 & $12.8 \pm 0.000$ & $14.3 \pm 0.015$ & 0.005 \\
\hline
\end{tabular}

Notes: Staphylococcus aureus (SA); Staphylococcus epidermidis (SE);Pseudomonas aeruginosa (PA); 0.5\% chloramphenicol+0.02\%Thimerosal (FA);0.02\%Thimerosal (FA1); $0.5 \%$ chloramphenicol+0.015\%Thimerosal (FB); $0.015 \%$ Thimerosal (FB1); $0.5 \%$ chloramphenicol+0.01\%Thimerosal (FC); $0.01 \%$ Thimerosal (FC1); $0.5 \%$ chloramphenicol+0.005\%Thimerosal (FD); $0.005 \%$ Thimerosal (FD1); $0.5 \%$ chloramphenicol+0.001\% Thimerosal (FE); 0.001\% Thimerosal (FE1); Each number of experiment replication= 3, Diameter of inhibition (mean \pm SD)

Both the neomycin sulfate and chloramphenicol eye drop formula found that the higher the concentration of thimerosal used, the greater the diameter of inhibition. There was a significant difference in the inhibitory potency between formulas containing thimerosal, 
compared to single thimerosal at related concentrations. The higher the concentration of thimerosal, the lower the rate of growth of the bacteria. But the smaller the concentration of preservatives used, the risk of side effects in eye drops can be reduced. Preservatives in eye drops are limited in concentration because they can cause side effects such as irritating the eyes and damaging the surface of the eyeball [29]. After determining the thimerosal concentration, the smallest effective concentration was $0.001 \%$, thimerosal remains to provide antibacterial activity against all tested bacteria.

\section{Clarity observation}

Visual observation of eye drop preparations is needed to find out the presence of particles and supports the quality of eye drops. The assessment of eye drops clarity can be observed visually on white and black background in suitable lighting. The three formulas of each eye drop preparation showed that the eye drops were clear and there was no color change during the storage period.

\section{pH}

Measurement of $\mathrm{pH}$ in eye drops is very useful to prevent pain or eye discomfort after the use of eye drops. $\mathrm{pH}$ incompatibility in eyes may cause irritation and the drug bioavailability decreased because the tearing was increased [30]. Several studies mentioned that the $\mathrm{pH}$ range that can still be accepted by the eye is between $\mathrm{pH}$ 5.5-11.4, the range of 4-8 or the optimum $\mathrm{pH}$ for eye drops that equals tear fluid and is about $7.4[30,31]$. Therefore, the $\mathrm{pH}$ of eye drops must be made to comply with the $\mathrm{pH}$ range that is suitable for the eye. The $\mathrm{pH}$ stability of the preparation is an important parameter in the evaluation of eye drop preparations, because $\mathrm{pH}$ changes not only result in unexpected side effects, $\mathrm{pH}$ also affects the action of the drug.

$\mathrm{pH}$ changes in the both eye drops were measured for $28 \mathrm{~d}$ of storage using a $\mathrm{pH}$ meter. The $\mathrm{pH}$ of each eye drops solution changed over storage time. The $\mathrm{pH}$ changes of neomycin sulfate eye drops formulations were in the range of 6.45 to 6.60 . It was found that there was a pH decreasing in F0 of neomycin sulfate eye drops formula, from 6.60 decreasing to 6.45 after $28 \mathrm{~d}$ of storage. Whereas F1 and F2 that are containing thimerosal, tend to be relatively stable, ranging from 6.60 to 6.60 after $28 \mathrm{~d}$ of storage. Unlike the chloramphenicol eye drops, changes in $\mathrm{pH}$ between $\mathrm{F} 0$ with $\mathrm{F} 1$ and F2 were not significantly different. Nevertheless, the highest $\mathrm{pH}$ decrease occurred at F0, from $\mathrm{pH} 7.19$ down to 7.10. While the decrease in $\mathrm{pH}$ of $\mathrm{F} 1$ and $\mathrm{F} 2$ was 7.21 to 7.13 and 7.22 to 7.14 respectively. The decreasing in $\mathrm{pH}$ among two eye drop solutions might because of the different buffering agent used in the formula, that has an important role in $\mathrm{pH}$ maintaining. The common buffer agents used in the formula of ophthalmic solutions are phosphate, citrate phosphate, citrate, acetate, bicarbonate, and borat [32]. Phosphate is the most-used buffer agent, as buffer agent used in the formula of neomycin sulfate in this study. Meanwhile, in cloramphenicol eye drops formula used boric acid.

However, all $\mathrm{pH}$ formulas from both eye drops still comply the required $\mathrm{pH}$ of the eye drops. The $\mathrm{pH}$ values will describe the eye drop solution formula that are most compatible with eye physiology and are more stable during the storage time. The $\mathrm{pH}$ stability of each eye drop preparation formula containing $05 \%$ neomycin sulfate and $0.5 \%$ chloramphenicol, can be observed in table 5 and fig. 1-2.

\section{Sterility test}

The basic characterization of eye drops as sterile preparations are totally free from all contaminants. The sterility of eye drop were required to be maintained during the period of use [33]. The sterility test of eye drop preparations includes fertility test, effectiveness test, and sterility test. In the fertility test, the used media showed growth of the bacteria and fungi used. This showed that the media can grow microorganisms so that they can be used for sterility tests for eye drops. The effectiveness test was useful to prove that the growth media was able to grow microorganisms after inoculating with the eye drop sample. The used media were FTM, which was implanted by Bacillus subtilis and TSB bacteria which were implanted with Candida albicans.

The sterility of the products can be determined by observing the turbidity of the media after incubated for 14 at $30-35{ }^{\circ} \mathrm{C}$ for FTM media and at a temperature of $20-25^{\circ} \mathrm{C}$ for TSB media [34]. All eye drops formulas were found as a sterile product during the storage time. This result suggested that the sterilization process of all formulas was done successfully because both F0 of the eye drops showed to be sterile after direct inoculation and there were not any microbial growth found in the media. Therefore, based on these sterility results, thimerosal role's as the preservative agent in F1 and F2 formula, could not be explained.

Table 5: The pH changes of $0.5 \%$ neomycin sulfate and $0.5 \%$ chloramphenicol eye drops over storage time

\begin{tabular}{|c|c|c|c|c|c|c|}
\hline \multirow[t]{2}{*}{ Days } & \multicolumn{3}{|c|}{ pH of $0.5 \%$ neomycin sulfate } & \multicolumn{3}{|c|}{ pH of $0.5 \%$ chloramphenicol } \\
\hline & F0 & F1 & F2 & F0 & F1 & F2 \\
\hline 1 & $6.55 \pm 0.000$ & $6.66 \pm 0.000$ & $6.66 \pm 0.000$ & $7.19 \pm 0.000$ & $7.21 \pm 0.000$ & $7.22 \pm 0.000$ \\
\hline 3 & $6.55 \pm 0.000$ & $6.66 \pm 0.000$ & $6.66 \pm 0.000$ & $7.18 \pm 0.000$ & $7.20 \pm 0.000$ & $7.22 \pm 0.000$ \\
\hline 7 & $6.53 \pm 0.000$ & $6.65 \pm 0.000$ & $6.64 \pm 0.000$ & $7.17 \pm 0.000$ & $7.19 \pm 0.000$ & $7.21 \pm 0.000$ \\
\hline 14 & $6.51 \pm 0.000$ & $6.63 \pm 0.000$ & $6.62 \pm 0.000$ & $7.16 \pm 0.000$ & $7.17 \pm 0.000$ & $7.20 \pm 0.000$ \\
\hline 21 & $6.49 \pm 0.005$ & $6.61 \pm 0.000$ & $6.60 \pm 0.000$ & $7.13 \pm 0.005$ & $7.14 \pm 0.005$ & $7.17 \pm 0.000$ \\
\hline 28 & $6.45 \pm 0.005$ & $6.60 \pm 0.005$ & $6.60 \pm 0.000$ & $7.10 \pm 0.000$ & $7.13 \pm 0.005$ & $7.14 \pm 0.005$ \\
\hline
\end{tabular}

Notes: Each number of experiment replication $=3$; pH changes ((mean \pm SD)

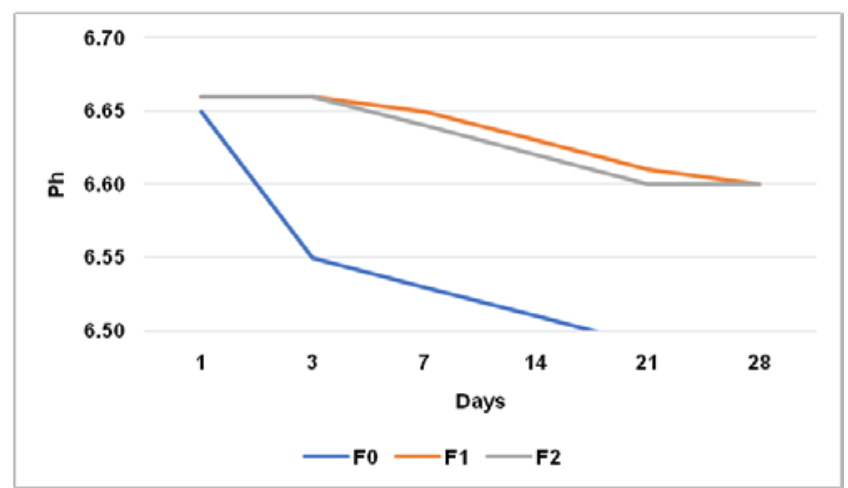

Fig. 1: The $\mathrm{pH}$ changes of $0.5 \%$ neomycin sulfate eye drops over storage time, Notes: Each number of experiment replication= 3 ; $\mathrm{pH}$ changes (mean \pm SD) 


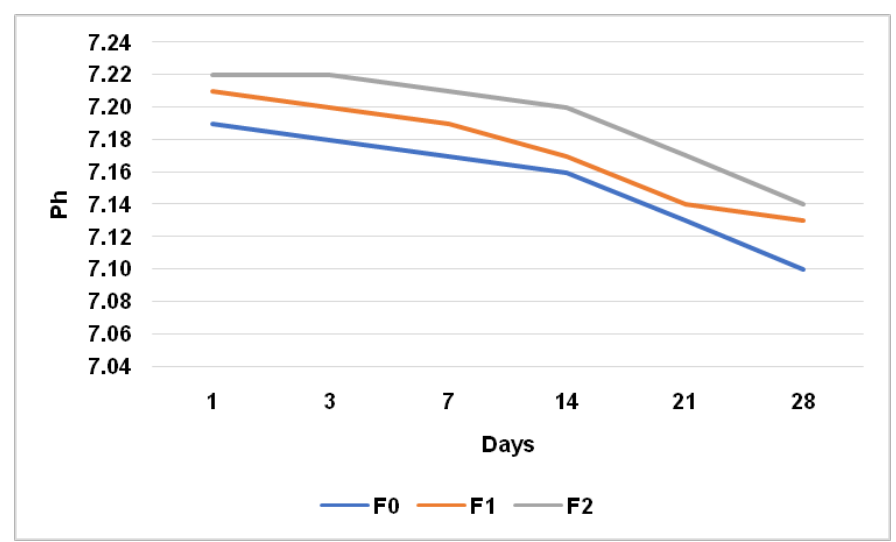

Fig. 2: The $\mathrm{pH}$ changes of $0.5 \%$ chloramphenicol eye drops over storage time mean, notes: Each number of experiment replication= 3; pH changes (mean $\pm \mathrm{SD})$

\section{Efficacy test}

This study compared the antibacterial effectiveness of eye drops with thimerosal preservative at a concentration of $0.001 \%$ (F2) to the negative control (F0) and determine the effect of differences in thimerosal concentration compared with the positive control (F1). The efficacy test result during the storage time could be seen in table 6-7. All the formulas exhibited strong antibacterial against $S$. aureus, $S$. epidermidis, and $P$. aeruginosa. The most sensitive pathogen against all formulas was $S$. aureus. To determine the effect of thimerosal, the comparison antibacterial test between formula with the thimerosal addition (F1 and F2) and without thimerosal (F0). The efficacy test demonstrated that the existence of thimerosal in the formula, improving the antibacterial potency of the formula by observing the inhibitory diameter increasing. This combination produced a synergistic effect of the antibiotics and the thimerosal as a preservative agent against common eye pathogens. The formulas of chloramphenicol eye drops produced bigger diameter of inhibition than neomycin sulfate. These results were because of the different $\mathrm{pH}$ solution ranges. The $\mathrm{pH}$ of chloramphenicol eye drops were closely at neutral $\mathrm{pH}$, while the neomycin sulfate were grouped into the weak acid solution. The different buffer component gave the main effect to $\mathrm{pH}$ values of the formulas. The $\mathrm{pH}$ values were reported gave an essential impact to thimerosal's work. Thimerosal is stable in weak alkaline or neutral $\mathrm{pH}$ [35]; thus the effectivity of thimerosal in chloramphenicol eye drops was better than in neomycin sulfate.

Table 6: Antibacterial efficacy of $0.5 \%$ neomycin sulfate eye drop

\begin{tabular}{|c|c|c|c|c|c|c|c|c|}
\hline \multirow[t]{2}{*}{ Formula } & \multirow[t]{2}{*}{ Bacteria } & \multicolumn{6}{|c|}{ Diameter of inhibition (mm) } & \multirow[t]{2}{*}{ \%decrease } \\
\hline & & 1 & 3 & 7 & 14 & 21 & 28 & \\
\hline \multirow[t]{3}{*}{ F0 } & SA & $22.2 \pm 0.000$ & $22.2 \pm 0.000$ & $21.2 \pm 0.000$ & $20.5 \pm 0.005$ & $18.7 \pm 0.000$ & $17.8 \pm 0.000$ & 19.8 \\
\hline & SE & $23.0 \pm 0.000$ & $22.8 \pm 0.005$ & $20.4 \pm 0.000$ & $20.1 \pm 0.000$ & $20.1 \pm 0.000$ & $19.2 \pm 0.002$ & 16.5 \\
\hline & PA & $21.2 \pm 0.000$ & $20.9 \pm 0.004$ & $20.0 \pm 0.000$ & $19.0 \pm 0.005$ & $18.1 \pm 0.000$ & $14.0 \pm 0.000$ & 33.9 \\
\hline \multirow[t]{3}{*}{$\mathrm{F} 1$} & SA & $23.3 \pm 0.002$ & $22.9 \pm 0.000$ & $22.3 \pm 0.005$ & $21.2 \pm 0.005$ & $20.0 \pm 0.000$ & $19.7 \pm 0.000$ & 15.4 \\
\hline & SE & $20.3 \pm 0.001$ & $19.9 \pm 0.000$ & $19.3 \pm 0.005$ & $19.0 \pm 0.000$ & $18.6 \pm 0.005$ & $18.1 \pm 0.000$ & 10.8 \\
\hline & PA & $23.5 \pm 0.000$ & $23.3 \pm 0.005$ & $22.7 \pm 0.004$ & $21.7 \pm 0.000$ & $20.1 \pm 0.000$ & $19.3 \pm 0.000$ & 17.8 \\
\hline \multirow[t]{3}{*}{ F2 } & SA & $22.3 \pm 0.005$ & $22.3 \pm 0.000$ & $21.4 \pm 0.005$ & $21.1 \pm 0.000$ & $18.9 \pm 0.000$ & $18.0 \pm 0.000$ & 19.2 \\
\hline & SE & $22.1 \pm 0.000$ & $22.0 \pm 0.004$ & $20.2 \pm 0.000$ & $20.0 \pm 0.000$ & $19.0 \pm 0.000$ & $18.8 \pm 0.005$ & 14.9 \\
\hline & PA & $22.3 \pm 0.000$ & $22.2 \pm 0.000$ & $20.8 \pm 0.000$ & $19.6 \pm 0.005$ & $19.0 \pm 0.000$ & $18.6 \pm 0.000$ & 16.5 \\
\hline
\end{tabular}

Notes: Each number of experiment replication= 3 (triplo); Diameter of inhibition (mean \pm SD)

During the storage time, the antibacterial efficacy of all formulas tends to be decreased. Among all formulas, F0 showed the significant inhibitory diameter decrease. This data informed that the thimerosal had an important role in inhibiting the bacterial growth. Based on statistical analysis for the interaction between the formula factor of neomicyn sulfate eye drops on the inhibitory diameter, resulted that $F_{\text {count }}(770.875)$ was greater than $F_{\text {table }}(3.168)$, thus $\mathrm{H}_{0}$ was rejected. It described that there was a difference in the effect of the formula on the inhibitory diameter. In other words, each formula (F0, F1, and F2) showed different inhibition diameters. F0 preparations experienced a significant decrease in effectiveness compared to F1 and F2. While the difference in the decrease in the effectiveness of F1 and F2 was not significant, therefore, considering the thimerosal side effect in high-level doses, the insignificant difference in the effectiveness of F1 and F2 could be the logic reason to use $0.001 \%$ thimerosal preservatives in the eye drop formulas than $0.01 \%$ thimerosal. Whereas, based on the influence of bacterial type factors on inhibitory diameter, it was found that $F_{\text {count }}$ $(127,392)$ was greater than $F_{\text {table }}(3,168)$ so that $H_{0}$ was rejected. This showed that there were differences in the effect of bacterial types on inhibitory diameter. In other words, each formula of $0.5 \%$ neomycin sulfate eye drops provides different effectiveness for each test bacteria. Likewise, for storage period factor, $F_{\text {count }}(773,474)$ was greater than $\mathrm{F}_{\text {table }}(2,386)$ so $\mathrm{H}_{0}$ was rejected. This showed that the difference in storage effect on inhibitory diameter. By the increasing of storage time, the diameter of the inhibition formed was smaller, meaning the effectiveness of the preparation decreases. Based on Student Newman Keuls (SNK test), there were significant results for each test bacteria, formula, and storage period of inhibitory diameter and conclusion that $S$. aureus had the highest average inhibitory diameter, meaning that the bacteria were the most influential against $0.5 \%$ neomycin sulfate eye drops.

The same analysis result was obtained from ANOVA statistycal calculation for $0.5 \%$ chloramphenicol eye drops. There were influences between the formula factor, bacterial type and storage time on the inhibitory diameter of each chloramphenicol eye drops formula. Based on the Newman-Keuls test, it was known that there were differences in the effect of dosage formulas, storage times and test bacteria. Interaction of dosage formulas with storage time, storage time with test bacteria, and dosage formulas with significant test bacteria in all chloramphenicol eye drops. These data indicated that the use of thimerosal preservatives proved to be needed in the eye drops formulation to reduce the diameter of the inhibitory decreasing. 
Table 7: Antibacterial efficacy of $0.5 \%$ chloramphenicoleye drop

\begin{tabular}{|c|c|c|c|c|c|c|c|c|}
\hline \multirow[t]{2}{*}{ Formula } & \multirow[t]{2}{*}{ Bacteria } & \multicolumn{6}{|c|}{ Diameter of inhibition (mm) } & \multirow[t]{2}{*}{ \% decrease } \\
\hline & & 1 & 3 & 7 & 14 & 21 & 28 & \\
\hline \multirow[t]{3}{*}{ F0 } & SA & $36.7 \pm 0.000$ & $34.8 \pm 0.000$ & $32.4 \pm 0.000$ & $31.7 \pm 0.005$ & $29.6 \pm 0.000$ & $28.7 \pm 0.004$ & 21.7 \\
\hline & SE & $31.9 \pm 0.000$ & $30.7 \pm 0.002$ & $29.4 \pm 0.002$ & $27.7 \pm 0.000$ & $25.6 \pm 0.000$ & $23.6 \pm 0.000$ & 26.0 \\
\hline & PA & $26.7 \pm 0.000$ & $25.8 \pm 0.000$ & $24.4 \pm 0.000$ & $22.6 \pm 0.005$ & $20.6 \pm 0.000$ & $17.8 \pm 0.000$ & 33.3 \\
\hline \multirow[t]{3}{*}{$\mathrm{F} 1$} & SA & $38.4 \pm 0.005$ & $37.7 \pm 0.000$ & $36.6 \pm 0.000$ & $35.5 \pm 0.000$ & $34.8 \pm 0.000$ & $32.9 \pm 0.000$ & 14.3 \\
\hline & SE & $33.5 \pm 0.000$ & $32.8 \pm 0.000$ & $31.8 \pm 0.000$ & $30.5 \pm 0.000$ & $28.9 \pm 0.000$ & $26.4 \pm 0.000$ & 21.1 \\
\hline & PA & $29.8 \pm 0.000$ & $28.5 \pm 0.005$ & $26.6 \pm 0.005$ & $24.5 \pm 0.000$ & $22.9 \pm 0.000$ & $21.9 \pm 0.005$ & 26.5 \\
\hline \multirow[t]{3}{*}{ F2 } & SA & $37.4 \pm 0.004$ & $36.6 \pm 0.000$ & $35.4 \pm 0.000$ & $34.0 \pm 0.000$ & $33.7 \pm 0.000$ & $31.8 \pm 0.000$ & 14.9 \\
\hline & SE & $32.6 \pm 0.000$ & $31.9 \pm 0.004$ & $30.8 \pm 0.000$ & $28.9 \pm 0.005$ & $27.6 \pm 0.000$ & $25.9 \pm 0.000$ & 20.5 \\
\hline & PA & $27.4 \pm 0.000$ & $26.6 \pm 0.000$ & $24.4 \pm 0.000$ & $23.4 \pm 0.000$ & $20.7 \pm 0.000$ & $18.8 \pm 0.000$ & 31.3 \\
\hline
\end{tabular}

Notes: Each number of experiment replication= 3 (triplo); Diameter of inhibition (mean \pm SD)

\section{CONCLUSION}

In conclusion, the investigated effect of thimerosal as a preservative agent was very essential in supporting the quality and efficacy of eye drop products containing neomycin sulfate and chloramphenicol.

\section{ACKNOWLEDGMENT}

The authors are thankful to Triana Yulandani and Narumi Sekar Sukmandari for the contributions to carry out this study.

\section{AUTHORS CONTRIBUTIONS}

All the authors have contributed equally

\section{CONFLICTS OF INTERESTS}

\section{Declared none}

\section{REFERENCES}

1. Menzies D, Bourbeau J. Building-related illnesses. N Engl J Med 1997;337:1524-31.

2. Stone V. Environmental air pollution. Am J Respir Crit Care Med 2000;162:S44-7.

3. Nunes ZG, Martins AS, Altoe AL. Indoor air microbiological evaluation of offices, hospitals, industries, and shopping centres. Mem Inst Oswaldo Cruz 2005;100:351-7.

4. Kusuma SAF, Hendriani R, Genta A. Antimicrobial spectrum of red piper betel leaf extract (Piper crocatum Ruiz and Pav) as natural antiseptics against airborne pathogens. J Pharm Sci Res 2017;9:583-7.

5. Mayo MS, Schlitzer RL, Ward MA, Wilson LA, Ahearn DG. Association of pseudomonas and serratia corneal ulcers with use of contaminated solutions. J Clin Microbiol 1987;25:1398-400.

6. Donzis PB. Corneal ulcer associated with contamination of aerosol saline spray tip. Am J Ophthalmol 1997;124:394-5.

7. Snyder RW, Glasser DB. Antibiotic therapy for ocular infection. West J Med 1994;161:579-84.

8. Templeton WC. $3^{\text {rd }}$ Eiferman RA, Snyder JW, Melo JC, Raff MJ. Serratia keratitis transmitted by contaminated eyedroppers. Am J Ophthalmol 1982;93:723-6.

9. Schein OD, Wasson PJ, Boruchoff SA, Kenyon KR. Microbial keratitis associated with contaminated ocular medications. Am J Ophthalmol 1988;105:361-5.

10. Perry HD, Donnenfeld ED. Issues in the use of preservative-free topicals. Manag Care 2003;12:39-41.

11. Jokl DH, Wormser GP, Nichols NS, Montecalvo MA, Karmen CL. Bacterial contamination of ophthalmic solutions used in an extended care facility. Br J Ophthalmol 2007;91:1308-10.

12. Fazeli MR, Nejad HB, Mehrgan H. Microbial contamination of preserved ophthalmic drops in outpatient departments: possibility of an extended period of use. Daru 2004;12:151-6.

13. Geyer O, Bottone EJ, Podos SM, Schumer RA, Asbell PA. Microbial contamination of medications used to treat glaucoma. Br J Ophthalmol 1995;79:376-9.

14. Stevens JD, Matheson MM. Survey of the contamination of eyedrops of hospital inpatients and recommendations for the changing of current practice in eyedrop dispensing. Br J Ophthalmol 1992;76:36-8.

15. Brudieu E, Duc DL, Masella JJ, Croize J, Valence B, Meylan I, et al. Bacterial contamination of multi-dose ocular solutions. A prospective study at the Grenoble Teaching Hospital. Pathol Biol (Paris) 1999;47:1065-70.

16. Tasli H, Cosar G. Microbial contamination of eye drops. Cent Eur J Public Health 2001;9:162-4.

17. Feghhi M, Mahmoudabadis AZ, Mehdinejad M. Evaluation of fungal and bacterial contaminations of patient-used ocular drops. Med Mycol 2008;46:17-21.

18. Hooker B, Kern J, Geier D, Haley B, Sykes L, King P, et al. Methodological issues and evidence of malfeasance in research purporting to show thimerosal in vaccines is safe. BioMed Res Int 2014;1-8. http://dx.doi.org/10.1155/2014/247218

19. Maggs DJ, Miller P, Ofri R. Ocular pharmacology and therapeutics. Slatter's Fundamentals of Veterinary Ophthalmology. $4^{\text {th }}$ ed. Saunders, California; 2008.

20. Buckley SA. Survey of patients taking topical medication at their first presentation to eye casualty. Br Med J 1990;300:1497-8.

21. Kirkness CM, Seal DV, Hay J. Topical chloramphenicol: use or abuse? Eye 1995; 9:vii-viii.

22. Hall AV, Das SS, Tabaqchali S. Is it time to stop using chloramphenicol on the eye? Risk is low in short courses [Letter]. Br Med J 1995;311:450-1.

23. Sinclair NM, Leigh DA. A comparison of fusidic acid viscous eye drops and chloramphenicol eye ointment in acute conjunctivitis. Ther Res 1988;44:468-74.

24. Beasley H, Boltralik JJ, Baldwin HA. Chloramphenicol in aqueous humor after topical application. Arch Ophthalmol 1975;93:184-5.

25. Murugan N, Malathi J, Therese KL, Madhavan HN. Antimicrobial susceptibility and prevalence of extended-spectrum betalactamase (ESBL) and metallo beta-lactamase (MBL) and its coexixtence among Pseudomonas aeruginosa recovered from ocular infections. Int J Pharm Pharm Sci 2015;7:147-51.

26. Kusuma SAF, Abdassah M, Valas BE. Formulation and evaluation of anti-acne gel containing Citrus aurantifolia juice using carbopol as a gelling agent. Int J Appl Pharm 2018;10:147-52.

27. Kusuma SAF, Agung MUK, Ismail AA. Antibacterial activity of extracellular compounds produced by bacterial exosymbion on sponges against Staphylococcus aureus ATCC 25923 Biofilm. J Pharm Sci Res 2017;9:1682-5.

28. Kusuma SAF, Yus Hargono CY, Hendro W. Beta-lactamase enzyme role in minimizing false-positive result of cefotaxime injection end-product sterility. J Pharm Sci Res 2018;10:1036-40.

29. Bartlett JD, Siret JD. Clinical ocular pharmacologi. 4th ed. Butterwort Heinemann; 2001.

30. Jitendra PK, Sharma A, Banik Dixit S. A new trend: ocular drug delivery system. Int J Pharm Sci 2011;2:1-25.

31. Lukas S. Formulasi steril. Penerbit ANDI, Yogyakarta; 2006.

32. Valldecabres MG, Alemany AL, Fiacle, Refojo MF. pH stability of ophthalmic solutions. Optometry 2004;75:161-8.

33. British Pharmacopoeia. Efficacy of antimicrobial preservation. Vol. IV. Appendix XVI C A367-A369. The Stationery Office, London; 2007.

34. Kotecha RK, Bhadra S, Rajesh KS. Formulation and process development of azithromycin ophthalmic nanosuspension. Int J Pharm Pharm Sci 2013;5:490-7.

35. Van Horn DL, Edelhauser HF, Prodanovich G, Eiferman R, Pederson HF. Effect of the ophthalmic preservative thimerosal on rabbit and human corneal endothelium. Invest Ophthalmol Vis Sci 1977;16:273-80. 